\title{
AS CARTOGRAFIAS E OS ATLAS GEOGRÁFICOS ESCOLARES
}

\section{Cartography and School Atlases}

Prof. Dr. Marcello Martinelli

Universidade de São Paulo

Av. Prof. Lineu Prestes, 338, Butantã, CEP: 01060-970 - Sao Paulo, SP - Brasil

Tel/Fax: (+55 11) 30913769 / 30913159 - m_martinelli@superig.com.br

\section{$a_{a} a a_{a}$}

\section{Resumo}

Uma vez que os mapas desenhados pelo homem adiantado aos dos dias atuais, avanços mapeamento feito para alcançar um elevado nível de requinte. Este artigo irá brevemente mencioná-los e comentar que teria trazido contribuições para a metodologia do atlas escolar.

Palavras-chave: Cartografia, atlas, geografia escolar.

\begin{abstract}
From the maps traced out by primitive man to the highly technical diagrams of the present day, the science of cartography has made giant strides towards a high level of perfection. The present paper will provide a brief overview of this process and comment on its contributions to the methods used for the production of geographic atlases for schools.
\end{abstract}

Key words: Cartography, school atlases.

\section{Resumen}

Desde los mapas trazados por el hombre primitivo hasta aquellos de los días actuales, la cartografía dio largos pasos para alcanzar un nivel elevado de perfeccionamiento. El presente paper hará una breve mención sobre las mismas y comentará que contribuciones habrían traído a la metodología de los atlas geográficos escolares.

Mots-Clé: Cartographie, atlas, geographie scolaire.

\author{
aaCaa
}




\section{INTRODUÇÃO}

Desde o mapa da cidade Çatal Höyük da Turquia (6.200 a.C.) e o grafito de Bedolina (2.500 a.C.) até os mapas da era da informação, a cartografia deu largos passos para atingir um nível elevado de aperfeiçoamento, este sendo amparado por uma crescente busca de bases teórico metodológicas cada vez mais consistentes.

Com as concepções filosóficas dos gregos, que conferiram à Terra a forma de esfera, pode-se vislumbrar que, já então, tinha se iniciado a caminhada da cartografia em busca de uma afirmação científica.

Para o pensamento ocidental, o grande avanço da cartografia teria se dado centrado na Europa, estando relacionado com o Renascimento (séculos XIV e XVI), época em que começaram a surgir relações capitalistas. Com a intensificação do comércio entre o Ocidente e o Oriente, exigindo o desenvolvimento da navegação, houve grande ímpeto na necessidade de mapas, bem como na criação de meios para a respectiva orientação, esta se efetivando com a bússola provinda do extremo oriente. Confirmaram-se os Portulanos, mapas para navegar. Foram estabelecidos desde o fim da Idade Média, porém, agora, muito mais corretos, tendo para tal função uma rede de rosas dos ventos entrelaçadas.

A invenção da imprensa e da gravação foi um marco cultural do século XV que teve grande influência no progresso da cartografia, porquanto possibilitou a fácil reprodução de mapas, barateando seu custo unitário, permitindo maior difusão. Foi possível perceber, assim, a passagem do mapa registro, do mapa memória, para o mapa mercadoria.

Outro grande impulso à cartografia foi dado pelos grandes descobrimentos (séculos XV e XVI). Os interesses pela expansão do mercantilismo europeu engendraram enorme revolução espacial. As novas rotas marítimas acabaram por motivar uma articulação entre as várias partes do mundo de então. Desta feita, povos de outros continentes tornaram-se submissos ao modo de produção da burguesia européia. Navegantes, colonizadores e comerciantes exigiam mapas cada vez mais corretos. A busca crescente de mapas para registrar o mundo inteiro, bem como a procura de novos tipos de representações para questões específicas forçou a entrada da cartografia na manufatura, passo decisivo para ela integrar o processo capitalista de produção. Os mapas confirmaram-se como armas do imperialismo, promovendo a política colonial.

Chegando o século XVII, a proposta essencial da cartografia firmou-se na representação topográfica, livre de qualquer outra complementação. Buscou-se a precisão: localização e descrição minuciosa do que estava implantado à superfície da Terra.

Em sequência a esta postura, mais um significativo avanço na cartografia teve lugar no século XVIII, com a instituição de academias científicas, marcando assim o início da ciência cartográfica moderna. Grandes inovações foram propostas pelo astrônomo francês Cesar-François Cassini de Thury (1714/1784), que elaborou a primeira série sistemática de mapas topográficos para a França. Prezava-se uma maior perfeição na exata representação do território (LIBAULT, 1960).

Entretanto, a maior desenvoltura imprimida aos mapeamentos, como apoio aos novos conhecimentos, se deu com o aditamento do imperialismo, no fim do século XIX. Cada potência necessitaria de um inventário cartográfico preciso para as novas incursões exploratórias, incorporando assim, também esta ciência às suas investidas espoliativas nas áreas de dominação (PALSKY, 1984, 1996).

Contribuiu também para isto, o florescimento e sistematização dos diferentes ramos de estudos operados com a divisão do trabalho científico, no fim do século XVIII e início do século XIX, dentre os quais estava também a Geografia, fazendo com que se desenvolvesse, mediante acréscimos sucessivos, outra cartografia: a Cartografia temática, área de estudos atinente aos mapas temáticos (ROBINSON, 1982; ROBINSON et al, 1995; CAMBRÉZY e MAXIMY, 1995).

Esta cartografia não surgiu de forma espontânea; é historicamente sucessiva à visão topográfica do mundo. Sua emancipação norteou a passagem da representação das propriedades apenas "vistas", para a representação das propriedades "conhecidas" dos fenômenos de cunho geográfico. O código analógico foi substituído paulatinamente por um código mais abstrato. Passou-se a representar ca- 
tegorias mentalmente e não mais visualmente organizadas. Como produtos, os mapas temáticos se confirmaram como expressão do raciocínio que seu autor empreendeu diante da compreensão da realidade no contexto de determinado campo de estudos (PALSKY, 1996).

Nesse mesmo período, a cartografia como um todo teve um desenvolvimento particular, marcando uma época em que se iniciou a dar maior ênfase à técnica e à prática.

Já no intervalo entre o início da segunda metade do século XIX até antes das guerras pôde-se vislumbrar o esboço de uma conscientizarão para definir insumos em prol da cartografia se afirmar como um campo científico autônomo (ARNBERGER, 1970).

Assim é que, em 1921, Max ECKERT foi um dos primeiros a declarar a cartografia como ciência independente, vendo-a como separada da geografia e da geodésia. Com esta nova orientação, a ONU confirmou em 1949: "A cartografia é a ciência que trata da elaboração de mapas de todo tipo. Ela engloba todas as operações, desde os levantamentos básicos até a impressão final daqueles".

Foi no pós-guerra que, definitivamente a cartografia almejou constituir-se como Ciência.

Neste intento, um primeiro encaminhamento foi proposto pela Teoria da representação gráfica dos mapas desenvolvida por IMHOF, iniciando com a edição de seu primeiro compêndio "Gëlande und Karte" de 1950 e prosseguindo em outros estudos de 1962, 1965 e 1972.

Tal teoria ofereceria variada gama de tipos de conteúdos arranjando-os numa sequência de estruturas gráficas. Para a cartografia topográfica propôs reduzir a representação em estruturas dominantes. Para a cartografia temática estipulou concentrar a variedade de temas a representar em tipos, arranjando-os em uma sequência de estruturas gráficas. Assim os problemas das representações temáticas ficariam reduzidos ao processo de colocar o modelo de conteúdo na categoria adequada de modelo de representação gráfica. Esperava-se que tal teoria ao ter colhido sucesso no campo aplicado poderia, no futuro vir a ser produtiva também na área científica (KRETSCHMER, 1980).

No início da década de 1960 o estudo da Metacartografia de BUNGE (1962) teve significativa repercussão, bem como causou discussões. Nos anos seguintes ganhou mais reconhecimento no domínio da teoria da geografia do que no campo da cartografia.

Na metade da mesma década, despontaram os primeiros ensaios de cartografia computadorizada, onde fora possível fazer prévios tratamentos de dados. Todas as formas de representação foram realizadas por esses procedimentos. Facilitou a preparação de mapas. Ficara fácil adotar isolinhas para qualquer temática, seja da natureza, da sociedade, da economia. Assim a elaboração isarítmica tornou-se método para a análise espacial. Apesar disso, a cartografia digital não conduziu reflexões para uma nova base teórica para a ciência dos mapas.

No mesmo período emergiu uma inovação teórica bastante distinta da postura tradicional. BERTIN (1967) lucubrou uma concepção com bases na Semiologia, a Teoria Geral dos Signos. Esta fundamentou a proposta para uma linguagem da cartografia, que o autor denominou Representação gráfica. Integraria o sistema semiológico monossêmico. A monossemia não estaria entre os signos e seus significados, mas sim entre os significados dos signos. Sua estrutura comportaria como vaiáveis visuais sensíveis ao olhar, as duas dimensões do plano e mais seis modulações que qualquer mancha inscrita em tal plano pudesse assumir (MARTINELLI, 2008).

Paralelamente, no mesmo ano, compareceu uma nova elaboração trabalhada por vários pesquisadores de vários países como, BOARD (1967), KOLACNY (1969), KOEMAN (1971), assumindo as representações cartográficas como formas de comunicação visual confirmando a possibilidade de transmissão das informações por intermédio dos mapas. A assim chamada de Comunicação cartográfica foi considerada como uma postura mais promissora para compor a cartografia teórica.

Neste contexto deve-se lembrar que KEATES (1964) teria definido por primeiro o conceito de Comunicação Cartográfica, como também, MOLES (1964) teria considerado a cartografia como meio de comunicação. 
Tal propositura contou com o apoio da Teoria Geral dos Sistemas elaborada por BERTALANFFY em 1937, alcançando plena divulgação na década de 1950, a qual, por sua vez, fundamentou a Teoria Matemática da Comunicação de WEAVER e SHANNON (1949).

Apesar de sua boa aceitação, deve-se apontar que a principal base de sustentação de uma teoria cartográfica teria sido fortalecida por uma nova estrutura de pesquisa desenvolvida por RATAJSKI (1971). Nesta, o estudioso colocou o usuário numa posição central no contexto de todo o sistema, ao mesmo tempo em que reexaminou o processo cartográfico com particular esmero.

Nos anos que se seguiram, tanto a possibilidade de se empreender o ensino da cartografia baseado na teoria matemática da comunicação, como a questão sobre se tal teoria poderia servir de base para uma teoria geral da cartografia levantaram críticas (KRETSCHMER, 1980).

SALICHTCHEV (1973) após a sexta Conferência Internacional de Cartografia realizada no Canadá em 1972, dentre outras questões, fez críticas às idéias lá veiculadas dirigidas à subjetividade que estaria intrinsecamente ligada à informação cartográfica extraída do mapa pelo usuário, principalmente por conta da inclusão de anamorfoses dentre as representações.

O Professor advogou que a heterogeneidade de resgate de informação pelos leitores não se daria por conta da subjetividade da representação, mas sim devido aos diferentes níveis de extração da informação dependentes do preparo dos mesmos.

Para demonstrar tal processo, tomou de empréstimo o diagrama elaborado por KOLACNY (1969) e o rearranjou para exibir, não só os pontos onde haveria perdas, bem como aqueles onde resultariam ganhos de informação. Salientou, ainda, que o processo de comunicação cartográfica não deveria ficar apenas preso à Teoria Matemática da Comunicação, a qual considera somente as perdas de informação em cada etapa da comunicação, preocupando-se essencialmente com a minimização destes extravios. Era preciso considerar o valor cognitivo dos mapas.

Adentrando-se mais detidamente no processo de comunicação cartográfica poder-se-ia atentar para o fato de que no primeiro, segundo e terceiro estágios poderiam ocorrer perdas de informação, enquanto que no quarto e parcialmente no segundo contar-se-ia com ganhos. Isto se refletiria no maior ou menor desencontro entre o que foi considerado importante por quem fez o mapa e que seria reputado como significativo pelo usuário.

Outra concepção teórica para a cartografia lucubrada também nos anos 1960 deveu-se a ARNBERGER (1970), que desenvolveu os devidos fundamentos para confirmá-la como Ciência formal . Para essa asseveração, seria necessário trazer para a cartografia uma adaptação de métodos matemáticos, estatísticos, e geométricos. Os primeiros permitiriam calcular a perda de informação no interior das representações em mapas. Junto aos mapas quantitativos favoreceriam o cálculo das proporcionalidades entre tamanhos de figuras geométricas. Os métodos estatísticos forneceriam bases seguras às soluções vinculadas à definição das classes numéricas significativas para os mapas coropléticos. Por fim, os métodos geométricos teriam pronta aplicação para desenvolver representações em perspectiva, como os blocos-diagrama. Ainda, seriam aproveitados para a interpolação de isolinhas em mapas isarítmicos (KRETSCHMER, 1980).

Com início na década de 1960 e prosseguindo de forma mais apurada nos anos 1970 e 1980 contou-se com um acréscimo bastante significativo na busca de estabelecer bases científicas consistentes para a cartografia. Foi a idealização de TOBLER (1976) com sua Cartografia analítica, trazendo para a cartografia contribuições matemáticas, transformacionais e analíticas. Incluiria, assim, tópicos como, modelos de dados cartográficos, métodos e normas de levantamento de dados cartográficos digitais, transformações de coordenadas, generalização analítica e leitura analítica de mapas.

Foram todos os componentes dessa nova cartografia que acabaram por encaminhar diretrizes acertadas para a composição dos modernos sistemas de informações geográficas (SLOCUM et al., 2009).

Por sua vez, PETCHENIK (1977), fundamentada na psicologia cognitiva, considerou em sua 
reflexão sobre Cognição em cartografia, que os mapas não carregariam em si os significados, mas os desencadeariam na cabeça do usuário. Os signos apreendidos pelo leitor construiriam em sua mente o significado do conteúdo que foi formulado pelo construtor do mapa. Neste sentido, o significado dos mapas é resultado do arranjo espacial exibido. Não se prenderia aos objetos, mas sim ao conjunto de relações entre os objetos. O leitor deverá reconstruir em sua mente estas relações. Neste momento, o mapa passa a ter significado. É assim que se opera a compreensão em prol do conhecimento espacial através de mapas.

Na década de 1980, BRUNET e sua equipe divulgaram uma inovação bastante peculiar junto aos procedimentos de se idealizar e elaborar mapas. Tratou-se da Coremática. Sua exposição de forma mais detalhada fez parte de sua obra de 1987, "La carte: mode d'emploi”. É a ciência da análise e do uso dos coremas. É a gramática dos coremas.

Os coremas são arcabouços elementares de organização do território. Mostram estruturas ou dinâmicas. Exprimem como as sociedades organizam ou produzem seu espaço em função de recursos disponíveis e necessidades a serem atendidas.

A combinação de coremas de base cria modelos intermediários, que combinados em conjunção constroem, como produto final o mapa modelo. Será um modelo explicativo de uma situação geográfica. Visa exprimir a estrutura e a dinâmica da realidade apreendida de forma sintética.

Pronto o mapa modelo deve-se atentar que é o mapa em si que fala e não sua legenda. A linguagem do mapa estaria na forma, na estrutura, na dinâmica, no arranjo espacial e no significado das distribuições que mostra BRUNET (1987).

No final dos anos 1980 e início dos anos 1990 compareceu um modo bastante incisivo de se considerar a ciência dos mapas. Foi o da Cartografia crítica, fazendo críticas a essa área de estudos e aos SIG, em oposição às propostas de se elaborar mapas em bases científicas do após guerra. Isto, por verificar que a cartografia, em suas propostas, estaria produzindo mapas tidos como documentos científicos, neutros e apolíticos. Atenta a esta questão, a cartografia estaria iniciando a se libertar dos parâmetros acadêmicos e a se abrir mais para o público em geral (CRAMPTON e KRYGIER, 2008).

Graças aos grandes progressos da ciência da computação e da informática realizados sobremaneira nos últimos 20 anos do século XX, disponibilizando tecnologias avançadas, a cartografia foi enormemente beneficiada. Passou de analógica para digital. Assim, não só apresentou grande desenvolvimento na produção de mapas, como também possibilitou inúmeras iniciativas para novas representações a partir de dados georreferenciados. São as Transformações cartográficas. Elas estariam fundamentadas na valorização dos padrões espaciais que os atributos ou variáveis constroem, atentando mais para o respectivo aspecto morfológico do que se ater apenas para as constatações das distribuições geográficas. Com um olhar mais incisivo, estas propostas vieram sendo trabalhadas de forma mais específica por RIMBERT desde os anos de 1980 e 1990, certamente com laços no domínio da Cartografia analítica (RIMBERT, 1990).

Neste contexto, volta a ser exploradas representações que reportam distâncias, como já houve ensaios na década de 1950. Tais distâncias, em vez de serem reais, em quilômetros, seriam substituídas por distâncias outras, como as econômicas referentes aos custos de transporte. Pois, distâncias econômicas seriam mais realistas que as quilométricas (COLE, 1972; CAUVIN e RIMBERT, 1976; RIMBERT, 1990; CAUVIN, 1991; CHAMBRÉZY e MAXIMY, 1995; CAUVIN, 2008).

Salientam-se três representações. A primeira seria a que obriga as distâncias, bem como as unidades de observação onde se inserem, a se deformar a partir de um ponto selecionado, dentro ou fora delas, por conta da adoção de outra escala. As outras duas diriam respeito às que levam as unidades de observação a tornar-se de tamanhos proporcionais aos valores da variável explorada.

Seriam as Anamorfoses e os Cartogramas. Embora ambas possam ser chamadas de transformações cartográficas, em particular, os cartogramas contariam com propriedades que não os incluiriam no conjunto destas transformações, por conta de aceitarem vários resultados. 
As anamorfoses propriamente ditas seriam verdadeiras transformações cartográficas, mais apropriadamente denominadas de transformações cartográficas espaciais, por fazerem, graças a uma operação matemática, passar o mapa de um mesmo espaço, de uma para outra forma, privilegiando na visualização, o tema focalizado, além de admitirem uma única solução.

Tais transformações são realizadas a partir de uma superfície uniforme que sofreria dilatações ou contrações de maneira contínua, por conta de uma força que se modularia em função do maior ou menor valor da variável considerada.

Os Cartogramas são construções gráficas onde prevalece o tema. São elaborados justapondo-se sucessivamente as unidades de observação contíguas, peça por peça, passando a ficar de tamanhos proporcionais à variável em foco, com formato esquemático, geralmente quadrangular.

Ambas as representações ao assumirem deformações dificultam o reconhecimento da ordem geográfica agora diferente do hábito adquirido.

Frente aos preocupantes encaminhamentos da cartografia nas últimas décadas do século XX, quando ela se embateria com as propostas dos Sistemas de Informações Geográficas, com a participação de um bom número de estudiosos emergiu a Visualização como um aceitável método de pesquisa científica. A Visualização foi vista como a ciência da representação visual de dados para lhes assegurar a comunicação ou a compreensão (RHEINGANS, 1992).

Sua derivada, Visualização científica, intensamente pesquisada desde o final dos anos 1980, é a representação gráfica de dados como meio de adquirir conhecimento.

Assim, para a ciência dos mapas despontou como conceito central o de Visualização cartográfica. Este foi tido como uma forma de amalgamar os entendimentos da cartografia integrados à cognição e análise, à comunicação visual e não visual e às novas tecnologias computacionais vinculadas às novas técnicas de multimídia interativa ou não, dinâmica ou não. Contando com ampla difusão via internet, esta tripla associação de entendimentos perfez a base conceitual para a cartografia da atualidade.

A visualização vista como aglutinadora dos citados aspectos da cartografia não poderia se divorciar de seu contexto social, pois sem dúvida alguma, o conteúdo do mapa é muito mais importante do que as técnicas na história social da produção do saber cartográfico.

Uma outra cartografia da atualidade, que veio se consolidado desde a segunda metade da década de 1980, aglutinando grande merecimento, não pode deixar de ser mencionada: a Cartografia multimídia.

Assimilando o conceito de multimídia, tal cartografia ancorou-se na combinação integrada de representações em mapas com outras modalidades de mídia como, textos, imagens, infográficos, sons, animações e vídeos, possibilitando representações mais intuitivas e próximas da realidade com o intuito de viabilizar uma melhor compreensão do tema abordado. Conta-se com dois formatos de multimídia:

- a multimídia não-interativa, onde cada assunto a ser explorado se encadeia a um outro, como ao se consultar um livro;

- a multimídia interativa, onde o encadeamento dos assuntos é mais aberto, apresentando-os em seus relacionamentos, permitindo, assim, ao usuário navegar na informação consoante às necessidades de suas buscas (RAMOS, 2005; PETERSON, 2005).

No domínio da Cartografia multimídia se inserem também outros construtos como, a Visualização em três dimensões, o Mapa em 3D, a Realidade virtual e o Voo virtual.

Avançando além desta proposta, TAYLOR, em 1997 criou uma nova cartografia, a Cibercartografia. Desta disciplina constaria o multisensorial, a multimídia, a interatividade, a interdisciplinaridade, que seria aplicada a uma ampla variedade de temas; seria a parte de um pacote de infor- 
mações; seria confeccionada por equipes interdisciplinares, provendo a formação de novos grupos de pesquisa, integrando os governos e a sociedade civil (TAYLOR, 2003). O caminhar continuará...

\section{OS ATLAS GEOGRÁFICOS ESCOLARES}

No ensino-aprendizagem da Geografia, pelo menos naquele centrado na Europa, desde o inicio do século XIX, seguindo o modelo da geografia alemã, os Atlas geográficos escolares ganharam crédito entre os materiais didáticos.

Dentre tantos, o "Atlas général Vidal-Lablache: histoire et géographie” de 1894 foi um clássico que inspirou inúmeras derivações, tanto na França como em outros países do Velho Continente.

No Brasil, bem antes, em 1868 se publicava o Atlas do Império do Brazil de Cândido Mendes de Almeida, o primeiro Atlas escolar brasileiro.

A elaboração dos Atlas geográficos escolares não é simples. Não basta simplificar seus mapas, nem torná-los mais atraentes, muito menos selecionar os temas mais fáceis. Estes componentes devem ser ponderados, mas não são os essenciais. Tal tradição persiste negligenciando toda uma fundamentação metodológica específica. É assim que se vê, ainda hoje atlas escolares concebidos como compilações simplificadas dos atlas de referência.

Em seguida, ingressa-se nas bases metodológicas da geografia para compor os conteúdos dos Atlas. Conjugadamente estaria a definição do recorte espacial de abrangência desde o local até o mundial. Na sequência, considera-se a Cartografia Temática. A confecção dos mapas seriam elaborações que consideram a representação gráfica como uma linguagem, integrando um sistema semiológico monossêmico. Nesse contexto, os mapas temáticos dos Atlas podem ser construídos por vários métodos; cada um mais apropriado às manifestações (em ponto, em linha, em área) dos fenômenos da realidade, seja na abordagem qualitativa, ordenada ou quantitativa, seja numa apreciação estática, ou dinâmica. Ainda, a realidade a ser representada consentiria ser vislumbrada dentro de um raciocínio analítico ou de síntese. Assim, ter-se-ia de um lado a cartografia analítica - abordagem dos temas em mapas analíticos, atentando para seus elementos constitutivos, lugares, caminhos ou áreas caracterizadas por seus atributos ou variáveis. E de outro, uma cartografia de síntese - abordagem de temas em mapas de síntese, empreendendo a fusão dos seus elementos constitutivos em "tipos", perfazendo agrupamentos de lugares, caminhos ou áreas unitárias de análise caracterizadas por agrupamentos de atributos ou variáveis.

Será neste contexto que as diferentes cartografias terão oportunidade de colocar nesses atlas suas inovações, cada uma com seus méritos ou, quem sabe, em certos casos, certos desinteresses. Todas as possibilidades estariam abertas a rigorosos estudos para suas efetivas avaliações.

Junto ao fato da Geografia ter-se sistematizado como ciência no início do século XIX, em paralelo com o período em que se dava a divisão do trabalho científico para acatar os avanços da tecnologia em atendimento ao progresso industrial, contou-se também com a emergência da Cartografia temática.

Graças a ela, os atlas geográficos escolares puderam contar com mapas que iam além das referências geográficas, muito embora de forma tardia por pesar muito a tradição da localização e descrição geográfica.

A Teoria da representação gráfica dos mapas de IMHOF (1950) seria uma contribuição dirigida para a representação do relevo em pequenas escalas. Em geral, mapas do relevo com cores hipsométricas, sombreados e destaques de certas formas provindas dessas diretrizes marcaram presença nos atlas escolares.

De concepção mais teórica, e mais voltada à geografia, a Metacartografia não se fez notar de forma evidente junto aos atlas escolares.

No tocante à inovação teórica trazida por BERTIN (1967), estabelecendo as regras sintáticas de uma linguagem para a cartografia, a Representação gráfica, verifica-se que até hoje, a mesma 
não foi completamente assimilada. Assim, os mapas dos atlas, em sua grande maioria, infelizmente, não permitem que em suas legendas sejam praticadas reflexões sobre as relações que existiriam entre os significados dos signos, em vez de ficar apenas na tradicional relação entre o significado e o significante do signo, levando o aluno a estimular um nível de raciocínio mais elevado do que aquele que é comumente desenvolvido.

A Comunicação cartográfica, com grande difusão na década de 1970, mais fiel ao domínio acadêmico, teve, assim mesmo, sua contribuição com pesquisas relacionadas à eficácia dos mapas, sejam dos atlas geográficos ou de outras produções científicas ou não, na transmissão da informação.

A proposta da cartografia como Ciência formal não transpareceu na questão mais visual dos Atlas para escolares, seus mapas. Porém nada teria impedido que seus fundamentos constituíssem a base metodológica para a elaboração desses atlas por parte de seus autores.

A Cartografia analítica com suas contribuições muito específicas, também não se revelou, o que pode ser constatado mediante uma simples consulta dos atlas geográficos.

A partir dos subsídios proporcionados pelas pesquisas fundamentadas na Cognição em cartografia, como os estudos de PETCHENIK (1977) o entendimento do conteúdo dos mapas dos Atlas geográficos escolares poderiam ter passado a ter outro enfoque. Com esse encaminhamento, ter-se-ia que considerar que os signos apreendidos pelo aluno leitor construiriam em sua mente o significado do conteúdo que foi elaborado por quem traçou o mapa. Mas não se conhece avaliações nesse sentido.

Por outro lado, estes fundamentos encaminharam pesquisas em direção às questões sobre a construção da noção de espaço e sua representação pelas crianças, compatíveis com seu desenvolvimento mental, bases para a elaboração de uma metodologia dos mapas (OLIVEIRA, 1978).

Nesta linha, hoje se verifica uma boa presença de atlas geográficos escolares concebidos mediante esses ditames metodológicos.

A proposta da Coremática divulgada por BRUNET (1987) e sua equipe teve aplicações em atlas. É conhecido o "Brésil: un atlas chorématique" elaborado por THÉRY em 1986 e o "Atlas d'Espagne" de FERRAS (1986).

Pode-se acreditar, que embora com defesas pertinentes, atlas com essas soluções possam trazer alguma dificuldade, dependendo do nível de ensino, na compreensão, por utilizarem mapas como configurações esquemáticas, envolvendo certa complexidade ao apresentarem em formato de modelo uma exposição dinâmica da organização do espaço.

Os ditames da Cartografia crítica desenvolvida nos anos de 1980 e 1990 poderiam ter boa assimilação junto à concepção dos atlas geográficos escolares. Assim, poder-se-ia entrever atlas com mapas mais críticos diante das problemáticas desencadeadas junto ao homem e à natureza, oferecendo aos usuários uma leitura evidenciando a possibilidade de um espaço mais justo, ao mesmo tempo que abriria as portas para uma participação maior da sociedade em tais elaborações.

As Transformações cartográficas já se mostraram presentes nos atlas escolares da geografia. Não há dúvida nenhuma quanto o seu poder de valorização dos padrões espaciais que os atributos ou variáveis construíram. Entretanto a desfiguração da silhueta do território representado pode se afastar em muito do formato padrão da cartografia cartesiana, trazendo dificuldades na leitura da realidade para as pessoas que não têm familiaridade com essas novas visualizações.

Para amenizar esse desencontro poder-se-ia sugerir de se apor ao lado das Anamorfoses ou Cartogramas, não a representação temática em si, mas a base cartográfica do território em questão em seu formato original, antes das deformações introduzidas.

A Visualização Cartográfica veio para trazer enormes contribuições à lucubração dos atlas em níveis escolares, sejam digitais (em CD-ROM), sejam eletrônicos (na WEB). Reunindo aspectos respeitáveis dos avanços ganhos em várias áreas científicas e tecnológicas, oferece um espectro significativamente amplo de encaminhamentos para tais elaborações condizentes com a atualidade (LOCH, 2006). 
Porém deve ser lembrado que, para a composição dessas obras concebidas nos citados meios, tendo em vista um eficiente ensino e aprendizagem da geografia, deverá ser estabelecida uma metodologia de atlas bastante consistente.

Também a Cartografia multimídia apresentou inovações extremamente valiosas para a elaboração de atlas geográficos escolares. Toda sua proposta de integrar mapas a textos, imagens, infográficos, sons, animações e vídeos é válida para enaltecer o poder educativo de tais obras.

Pelo fato de se conjugar outras elaborações, dentre as quais, a Realidade virtual e o Voo virtual, a chance para um maior êxito na aprendizagem adviria do fato de se poder imergir o escolar em ambientes previamente estabelecidos conforme uma didática geográfica.

Por sua vez a Cibercartografia corroboraria com todos esses avanços incluídos na Cartografia, trazendo possibilidades até pouco tempo atrás, inimagináveis. Um exemplo de elaboração de atlas com base nesta postura é o "Cybercartografpic atlas of Antarctica" proposto por TAYLOR. O fato de abranger o multisensorial, a multimídia, a interatividade, a interdisciplinaridade, ampliaria sobremaneira a capacidade de ensino e aprendizagem da geografia pelos atlas, além de promover a inclusão escolar para pessoas com deficiências.

Está-se, assim, diante de um panorama altamente promissor para os que se dedicam com invejável dedicação à "arte" de se fazer Atlas.

\section{REFERÊNCIAS BIBLIOGRÁFICAS}

ARNBERGER, E. Die Kartographie als Wissenschaft und ihre Beziehung zur Geographie und Geodäsie. Grundsatzfragen der Kartographie, 1-28, 1970.

BERTALANFFY, L. von. General system theory: foundations, development, application. New York: George Braziller Inc., 1968.

BERTIN, J. Sémiologie graphique: les diagrammes, les réseaux, les cartes. Paris: Mouton, Gauthier-Villars, 1967.

BOARD, C. Maps as models. In: CHORLEY, R.J. e HAGGET, P. (ed). Models in geography. London: Methuen \& Co. Ltd.,1967.

BRUNET, R. La carte: mode d'emploi. Paris: Fayard/Reclus, 1987.

BUNGE, W. Metacartography. In: Theoretical geography. Lund Studies in Geography. Series C, (1), 1962. CAMBRÉZY, L. e MAXIMY, R. (ed.) La cartographie en débat: représenter ou convaincre. Paris: Karthala-Orstom, 1995.

CAUVIN, C. Transformações cartográficas espaciais e anamorfoses. In: DIAS, M.H. (coord.). Os mapas em Portugal: da tradição aos novos rumos da cartografia. Lisboa: Edições Cosmos, 1991.

CAUVIN, C. Cartographie thématique: 3 - méthodes quantitatives et transformations attributaires. Paris: Hermes Sciences, 2008.

CAUVIN, C. e RIMBERT, S. La lecture numérique des cartes. Fribourg: Éditions Universitaires, 1976.

COLE, J.P. Geografia quantitativa. Rio de Janeiro: IBGE, 1972.

CRAMPTON, J.W. e KRYGIER, J. Uma introdução à cartografia crítica. In: ASCELRAD, H. (org.). Cartografias sociais e território. Rio de Janeiro: IPPUR/UFRJ, 2008.

IMHOF, E. Gëlande und Karte. Zürich: Erlenbach, 1950.

KEATES, J.J. Cartographic communication, Abstract of Papers, (1034), 1964.

KOEMANN, C. The principle of communication in cartography. International Yearbook of Cartography, (11): 168-176, 1971.

KOLACNY, A. Cartographic information: a fundamental term in modern cartography. Cartographic Journal, (6): 47-49, 1969.

KRETSCHMER, I. Theoretical cartography: position and tasks. International Yearbook of Cartography: 142-155, 1980. 
LIBAULT, A. Histoire de la cartographie. Paris: Chaix, 1960.

LOCH, R.E.N. Cartografia: representação, comunicação e visualização de dados espaciais. Florianópolis: Editora da UFSC, 2006.

MARTINELLI, M. Mapas da geografia e cartografia temática. São Paulo: Editora Contexto, 2008.

MOLES, A. Théorie de l'information et message cartographique. Revue Française des sciences et des techniques, (32) : 11-16, 1964.

OLIVEIRA, L. Estudo metodológico e cognitivo do mapa. São Paulo: USP-IG, 1978.

PALSKY, G. Des représentations topographiques aux représentations thématiques. Recherches historiques sur la communication cartographique. Bulletin Association des Géographes Français, (506): 389-398, 1984.

PALSKY, G. Des chiffres et des cartes: la cartographie quantitative au XIXe siècle. Paris: Comité des Travaux Historiques et Scientifiques, 1996.

PETCHENIK, B.B. Cognition in cartography. Cartographica: the nature of cartographic communication. Monograph, (14): 117-128, 1977.

PETERSON, M.P. (ed.). Maps and internet. New York: Elsevier Ltd., 2005.

RAMOS, C.S. Visualização cartográfica e cartografia multimídia: conceitos e tecnologias. São Paulo: Editora Unesp, 2005.

RATAJSKI, L. Kartologie: ein System theoretischer Kartographie. Vermessungstechnik, 19 (9): 324-328, 1971.

RHEINGANS, P. Color change and control for quantitative data display. Proceedings of Visualization '92, 252-259, 1992.

RIMBERT, S. Carto-graphies, Paris: Hermes, 1990.

ROBINSON, A.H. Early thematic mapping in the history of cartography. Chicago: The University of Chicago Press, 1982.

ROBINSON, A.H. et al. Elements of cartography. ( $6^{\text {a }}$ ed.). New York: John Wiley \& Sons, 1995.

SALICHTCHEV, K. A. Some reflections on the subject and method of cartography after the Sixth International Cartographic Conference. The Canadian Cartographer, 10 (2): 106-111, 1973.

SLOCUM, T.A. et al. Thematic cartography and geovisualization. New Jersey: Pearson Education Inc., 2009.

TAYLOR, D.R.F. The Concept of Cybercartography. In: PETERSON, M.P. (ed.), Maps and the internet. Amsterdam: Elsevier, 2003.

THERY, H. Brésil: um atlas corématique. Paris/Montpellier: Fayard/Reclus, 1986.

TOBLER, W. Analytical cartography. The American Cartographer, 3(1): 21-31, 1976.

WEAVER e SHANNON. The mathematical theory of communication. Illinois: University of Illinois, 1949.

Trabalho enviado em agosto de 2011

Trabalho aceito em outubro de 2011 